\title{
Intestinal Parasitic Infections among HIV-Infected Patients on Antiretroviral Therapy Attending Debretabor General Hospital, Northern Ethiopia: A Cross-Sectional Study
}

This article was published in the following Dove Press journal:

HIVIAIDS - Research and Palliative Care

\author{
Ermias Alemayehu' \\ Alemu Gedefie' \\ Aderaw Adamu' \\ Jemal Mohammed' \\ Brhanu Kassanew ${ }^{2}$ \\ Berhanu Kebede (1D ${ }^{3}$ \\ Melaku Ashagrie Belete (D) \\ 'Department of Medical Laboratory \\ Science, College of Medicine and Health \\ Sciences, Wollo University, Dessie II45, \\ Ethiopia; ${ }^{2}$ Department of Medical \\ Laboratory Science, College of Medicine \\ and Health Sciences, Woldia University, \\ Woldia, Ethiopia; ${ }^{3}$ Department of Medical \\ Laboratory Science, College of Medicine \\ and Health Sciences, Semera University, \\ Semera, Ethiopia
}

Background: Parasitic infections are known causes of morbidity among HIV-infected patients with low $\mathrm{CD}^{+}$counts who are on antiretroviral therapy (ART), mainly as a result of immuno suppression. This study aimed to assess the extent of intestinal parasitic infection and related risk factors among HIV-infected patients attending ART clinic at Debretabor General Hospital, Northern Ethiopia.

Methods: A health facility-based cross-sectional study was conducted on 383 HIV-infected patients attending the ART clinic of Debretabor General Hospital, northern Ethiopia from December 2018 to March 2019. An interview-based structured questionnaire was used to gather sociodemographic and risk-factor data. About $5 \mathrm{~g}$ fresh stool and $4 \mathrm{~mL}$ venous blood were collected from each patient, then transported and tested in accordance with laboratorystandard operating procedures. Data obtained were entered into SPSS version 22.0 and analyzed. $P<0.05$ with $95 \%$ CI was considered statistically significant.

Results: The overall prevalence of intestinal parasites was $25.3 \%$, with $18 \%$ and $23.8 \%$ by direct wet-mount and formol ether-concentration technique, respectively. Eight (2.1\%) patients were infected by multiple parasites using the concentration technique. Ascaris lumbricoides was the most frequently identified parasite $(\mathrm{n}=23,25.3 \%)$. Parasitic infection was significantly higher among illiterates $(P=0.011)$, patients with CD4 count $<200$ cells $/ \mathrm{mm}^{3}(P<0.001)$, and those who did not have a toilet in their home $(P=0.049)$ than their counterparts.

Conclusion: Relatively higher prevalence of intestinal parasitic infection was found among HIV/AIDS patients. The distribution of intestinal parasites was greatly affected by illiteracy, reduced $\mathrm{CD}^{+}$counts, and absence of a toilet. Therefore, HIV/AIDS patients with low $\mathrm{CD} 4^{+}$ counts should be diagnosed consistently for intestinal parasites with routine stool examinations, and awareness creation should be advocated to be included as an essential component of ART-monitoring strategies for improved patient care.

Keywords: antiretroviral therapy, debretabor, HIV/AIDS, intestinal parasites, risk factors

\section{Introduction}

HIV is a challenging health problem worldwide. Based on a joint report from the World Health Organization (WHO) and United Nations Programme on HIV/AIDS, about 38 million individuals were living with HIV by the end 2019 globally and more than 1 million had died due to AIDS-related complications and diseases, about $69 \%$ of them residing in the sub-Saharan Africa region. ${ }^{1}$ This region is most
Alemu Gedefie

Department of Medical Laboratory

Science, College of Medicine and Health

Sciences, Wollo University, Dessie I I45,

Ethiopia

Tel +25 I-9-1386-7849;

$+251-918106000$

Fax +25I 333II5250

Email melakuashagrie@gmail.com;

alemugedefie@gmail.com 
harshly affected by the virus: WHO reports have revealed that approximately one in 25 adults $(3.7 \%)$ are currently living with the virus, which is estimated to be more than two-thirds the global burden of HIV. ${ }^{1}$ Mainly due to subsequent heightened immunosuppression, which usually occurs in the late phase of the disease, opportunistic infections are among the major health problems affecting HIV/ AIDS patients globally. Such immunosuppression most commonly exposes HIV patients to a wide range of parasitic and microbial attacks.

Parasitic infections, particularly intestinal parasites, are widely distributed globally: about 3.5 billion individuals worldwide are infected with intestinal parasites. ${ }^{2}$ Intestinal parasites are the main threat in developing countries, such as Ethiopia, and the threat has been noticeably heightened with the coexistence of large burden of HIV/AIDS and malnutrition in the area. The extent of intestinal parasitic infection is highest in sub-Sahara African countries, where the highest proportion of HIV/AIDS cases are located. Evidence shows that HIV-infected patients are the most vulnerable risk group for acquiring parasitic and microbial infections. $^{3-5}$ Opportunistic infections, in particular parasitic infections, commonly affect people with HIV/AIDS and about $80 \%$ of AIDS patients die as a result of AIDSrelated infections, including the commonly occurring intestinal parasites, rather than due to the HIV infection itself. These opportunistic infections most commonly occur in the later stages of HIV infection, when the number of $\mathrm{CD}^{+} \mathrm{T}$ cells has declined mostly $<200 / \mathrm{mm}^{3.6}$

xxxDespite antiretroviral treatment (ART) improving the quality of life and reducing the occurrence of opportunistic infections among HIV/AIDS patients, ${ }^{1}$ those taking ART who have depleted $\mathrm{CD}^{+}$counts commonly suffer from intestinal parasitic infections due to immuno suppression. Malnutrition, poor waste management, ignorance (illiteracy), unhygienic sources of drinking water, and depleted $\mathrm{CD}^{+}$counts $\left(<200\right.$ cells $\left./ \mathrm{mm}^{3}\right)$ among HIV/ AIDS patients are the most common determinants of parasitic infections. ${ }^{4-9}$ The distribution of parasitic infection in developing countries is estimated to be as high as $95 \%$ among HIV-infected patients. ${ }^{10}$ In the same way as many other developing countries, particularly African countries, intestinal parasites are extensively distributed in Ethiopia, mainly associated with malnutrition, low socioeconomic status, poor personal and environmental hygiene, food contamination, and lack of potable water supply in rural and urban areas, principally resulting from inappropriate human excretus-disposal systems and lack of awareness regarding common health-promotion practices. ${ }^{9,11}$ Some studies have been conducted targeting the prevalence of intestinal parasites in different areas of Ethiopia; ${ }^{2,3,7-9,12,13}$ however, epidemiological data on the prevalence of intestinal parasitic infection among HIV/AIDS patients are still inadequate in the study area. Therefore, this study aimed to investigate the magnitude of intestinal parasitic infection and its related risk factors among HIV-infected patients attending the ART clinic of Debretabor General Hospital, northern Ethiopia.

\section{Methods}

\section{Study Design, Period, and Area}

This health facility-based cross-sectional study was conducted from December 2018 to March 2019 at Debretabor General Hospital, northern Ethiopia. Debretabor is located $654 \mathrm{~km}$ northwest of the capital - Addis Ababa, and has an average temperature of $14.8^{\circ} \mathrm{C}$. Debretabor General Hospital is a government health institutions providing health-care services to $>1$ million people, and had 4,326 HIV-infected patients attending ART during the study period.

\section{Sample-Size Determination and Sampling Technique}

A single population-proportion formula was employed to determine the sample size, taking $47.8 \%$ previous prevalence of intestinal parasites among HIV/AIDS patients ${ }^{7}$ with corresponding 5\% margin of error and $95 \%$ CI. In line with this, a total of 383 patients were included. Participants were selected and recruited using systematic sampling, taking the ART clinic registration book as a sampling frame. Patients who had taken any anthelminthic drugs within the prior 4 weekswere excluded.

\section{Data Collection and Laboratory Processing}

An interview-based structured questionnaire was deployed to gather information related to sociodemographic and health-related risk-factor data of study participants. About $5 \mathrm{~g}$ freshly passed stool was collected from each study participant using a prelabeled, leakproof, plastic container with screw-on lid and attached spoon (FL Medical, Italy) after appropriate collection instructions had been given to avoid specimen contamination. About $4 \mathrm{~mL}$ venous blood was collected from each study participant following appropriate collection procedures using 
an EDTA anticoagulated vacuum tube (Wego, China) by experienced laboratory personnel. Immediate processing of the specimens was performed in the hospital laboratory. Stool- and blood-specimen collection and processing were performed strictly following standard operating procedures.

\section{Stool Examination for Intestinal Parasites}

Direct examination of stool samples was carried out by emulsifying a portion of stool (about 1-2 mg) in a drop of physiological saline $(0.85 \%$ sodium chloride solution) and Lugol's iodine solution (for detecting the cystic stage of intestinal protozoan parasites). The remainder of thespecimen was preserved using $10 \%$ formalin after direct wetmount preparation and subsequently examined using the formol ether-concentration technique.

\section{Formol Ether-Concentration Technique}

In order to detect different stages of the intestinal parasites, the formol ether-concentration technique was performed by taking a pea-sized portion (estimated to be $1 \mathrm{~g}$ ) of representative stool sample using an applicator stick and emulsifying it in about $4 \mathrm{~mL} 10 \%$ formol-water solution within a screw-capped tube. An additional $4 \mathrm{~mL} 10 \%$ formol-water was added and mixed using vortex shaker. The suspension was then sieved (filtered) into a conical centrifuge tube and about 3-4 mL diethyl ether added and mixed for 1 minute. The tube was centrifuged at 3,000 rpm for about 1 minute. Finally, a portion of the sediment was examined microscopically using $10 \times$ and $40 \times$ objectives after being placed on a microscopic slide and covered using a coverslip. ${ }^{14}$ All positive findings from stool examination and parasitic species identification were approved by a senior medical laboratory technologist.

\section{CD4 T-Cell Determination}

$\mathrm{CD}^{+}$count $\left(\right.$cells $/ \mathrm{mm}^{3}$ ) analysis was performed on blood samples using a FACS count-automated machine (Becton Dickinson, USA) after quality control had been performed and passed. Once the reagent pair of tubes had been labeled and mixed using vortex with the pair upright and upside down for about 5 seconds, the tubes were then mixed with the patient's blood sample by inverting the tube five times after being opened using a coring station. About $50 \mu \mathrm{L}$ blood was pipetted into each tube, and the tubes were vortexed in the upright position for 5 seconds. Then, the tubes were incubated at room temperature in the dark for $60-120$ minutes, $50 \mu \mathrm{L}$ of fixative solution added to each, and mixed upright using the vortex for 5 seconds. After 30 minutes' incubation, the FACS count was run and results printed out. ${ }^{15}$

\section{Quality Assurance}

Standardized quality checks were performed throughout data collection to obtain reliable and quality research data. All queries in the interview-based structured questionnaire were prepared precisely and clearly and translated into the local language (Amharic). Training was given to all data collectors. Furthermore, all laboratorybased assays were performed based upon standard operating procedures, and quality-control procedures were strictly maintained throughout data collection.

\section{Statistical Analysis}

Data collected were entered and analyzed using SPSS version 22 (IBM, USA). Descriptive statistics and binary and multivariate logistic regression methods were used to analyze the data. Binary logistic regression was employed to show the correlation of the dependent variable with the individual independent variable.Multivariate logistic regression analysis was used to avoid confounders and identify risk factors autonomously impacting the occurrence of the dependent variable. $P<0.05$ with $95 \%$ CI was considered statistically significant.

\section{Ethical Approval and Consent to Participate}

After being thoroughly evaluated and checked for appropriateness, the study got approval from the Research Ethics Review Committee of the College of Health Sciences, Debretabor University, and ethical clearance was attained. Then, official collaboration and willingness were obtained from Debretabor General Hospital. Written and signed informed consent was obtained from individual study participants prior to commencing data collection. Positive results were immediately communicated to the ART-clinic physician, mentioning the parasitic species, and patients infected were treated with the appropriate protocol. This study was conducted in accordance with the Declaration of Helsinki.

\section{Results}

\section{Sociodemographic and Clinical Characteristics of Study Participants}

A total of 383 study participants were enrolled and investigated during the study period. The age of study participants ranged $18-65$ years, with a mean age of $37.1 \pm 11.5$ years. A 
majority $(50.9 \%)$ of study participants were aged 18-35 years. Of the total participants, 157 (41\%) were male and 226 (59\%) female. Nearly three-quarters $(281,73.4 \%)$ were urban dwellers, 169 (44.2\%) were married, and 150 (39.1\%) were single. Regarding education, 110 (28.7\%) had attended primary school. Almost all (92.4\%) had a toilet at home, $97.1 \%$ had a piped water supply in their home, and 26 (6.8\%) study participants had animal contact (Table 1). As for WHO clinical staging, about 248 (64.8\%) participants were stage I. Mean CD4 ${ }^{+}$count was 507 (28-2,417) cells/ $\mathrm{mm}^{3}$, and $156(40.7 \%)$ participants had a CD4 ${ }^{+}$count of 200-500 cells $/ \mathrm{mm}^{3}$ (Table 1).

Table I Socio-Demographic and Clinical Characteristics of HIV/ AIDS Patients Attending ART Clinic at Debretabor General Hospital $(n=383)$ from December 2018 to March 2019

\begin{tabular}{|c|c|c|c|}
\hline & & $\mathbf{n}$ & (\%) \\
\hline \multirow[t]{3}{*}{ Age, years } & $18-35$ & 195 & 50.9 \\
\hline & $36-53$ & 144 & 37.6 \\
\hline & $54-65$ & 44 & 11.5 \\
\hline \multirow[t]{2}{*}{ Sex } & Male & 157 & 41 \\
\hline & Female & 226 & 59 \\
\hline \multirow[t]{2}{*}{ Residence } & Urban & 281 & 73.4 \\
\hline & Rural & 102 & 26.6 \\
\hline \multirow[t]{4}{*}{ Marital status } & Single & 150 & 39.1 \\
\hline & Married & 169 & 44.2 \\
\hline & Divorced & 30 & 7.8 \\
\hline & Widowed & 34 & 8.9 \\
\hline \multirow[t]{5}{*}{ Education } & Illiterate & 88 & 23.0 \\
\hline & Can read and write & 39 & 10.2 \\
\hline & Primary & 110 & 28.7 \\
\hline & Secondary & 89 & 23.2 \\
\hline & College and above & 57 & 14.9 \\
\hline \multirow[t]{2}{*}{ Water source } & Piped & 372 & 97.1 \\
\hline & Well & II & 2.9 \\
\hline \multirow[t]{2}{*}{ Toilet in home } & Yes & 354 & 92.4 \\
\hline & No & 29 & 7.6 \\
\hline \multirow[t]{2}{*}{ Animal contact } & Yes & 26 & 6.8 \\
\hline & No & 357 & 93.2 \\
\hline \multirow[t]{4}{*}{ WHO clinical stage } & Stage I & 248 & 64.8 \\
\hline & Stage II & 103 & 26.9 \\
\hline & Stage III & 23 & 6.0 \\
\hline & Stage IV & 9 & 2.3 \\
\hline \multirow[t]{3}{*}{$\mathrm{CD4}^{+}$T-cell count } & $<200$ cells $/ \mathrm{mm}^{3}$ & 77 & 20.1 \\
\hline & $200-500$ cells $/ \mathrm{mm}^{3}$ & 156 & 40.7 \\
\hline & $>500$ cells $/ \mathrm{mm}^{3}$ & 150 & 39.2 \\
\hline
\end{tabular}

\section{Prevalence of Intestinal Parasites}

The overall prevalence of intestinal parasites among patients in this study was found to be $25.3 \%$. The prevalence of infection with one or more intestinal parasite using direct wet-mount and formol ether-concentration techniques was 69 of 383 (18\%) and 91 of 383 (23.8\%), respectively (Table 2). Mixed (double) infection was seen with the formol ether-concentration technique: eight $(2.1 \%)$ participants were infected by more than one parasite. Twelve species of intestinal parasites were identified in this study. Of these (positive on formol ether concentration), Ascaris lumbricoides 23 (25.3\%), Strongyloides stercoralis 15 (16.5\%), and Taenia spp. 12 (13.2\%) were predominantly detected (Table 2 ). The majority of intestinal parasitic infections were found among patients with $\mathrm{CD}^{+}$counts $<200$ cells $/ \mathrm{mm}^{3}$. Regarding the pattern of intestinal parasites among study participants in relation to their $\mathrm{CD}^{+}$counts, the occurrence of Entamoeba histolytica infections was significantly associated with $\mathrm{CD}^{+} \mathrm{T}$ cell count $<200$ cells $/ \mathrm{mm}^{3}(P=0.037$, Table 3$)$.

\section{Risk Factors Associated with Intestinal Parasitic Infection}

The prevalence of intestinal parasites was $28.2 \%$ in the agegroup 18-35 years and 29.5\% in the age-group 54-65 years, but the difference was not statistically significant $(P=0.193)$. Despite no statistically significant differences existing between intestinal parasites and sex, the prevalence of parasitic infection was relatively higher among men than women (29.3\% vs $22.6 \%$, AOR 1.025 , 95\% CI $0.558-1.882$; $P=0.937)$. Similarly, despite not reaching significance $(P=0.565)$, relatively higher prevalence of intestinal parasitosis was found among rural dwellers (Table 4).A positivity rate of almost a third $(n=28,31.8 \%)$ was found among illiterate study participants and was significantly associated with occurrence of intestinal parasites (AOR 4.165, 95\% CI 1.394 12.450; $P=0.011$ ). Moreover, educational status of being able to read and write only (AOR 9.329, 95\% CI 2.626, 33.140; $P=0.001$ ), absence of a home toilet (AOR 2.595, 95\% CI 1.003-6.712; $P=0.049)$, and $\mathrm{CD}^{+}$count $<200$ cells $/ \mathrm{mm}^{3}$ (AOR 3.359, 95\% CI 1.793-6.293; $P<0.001$ ) were found to be significantly association with intestinal parasitosis (Table 4).

\section{Discussion}

HIV infection is a major global public health problem, with the highest rates of disease found in sub-Saharan 
Table 2 Distribution of Specific Parasites by Different Diagnostic Techniques from HIVIAIDS Patients Attending ART Clinic at Debretabor General Hospital $(n=383)$ from December 2018 to March 2019

\begin{tabular}{|c|c|c|c|}
\hline & \multicolumn{2}{|l|}{ Diagnostic Method } & \multirow[t]{2}{*}{ Overall, n (\%) } \\
\hline & Direct Wet Mount, n (\%) & $\begin{array}{l}\text { Formol Ether } \\
\text { Concentration, n (\%) }\end{array}$ & \\
\hline Entamoeba histolytica trophozoite & $3(4.3)$ & 0 & $3(3.1)$ \\
\hline Entamoeba histolytica dispar cyst & $4(5.8)$ & $4(4.4)$ & $4(4.1)$ \\
\hline Giardia lamblia trophozoite & $3(4.3)$ & 0 & $3(3.1)$ \\
\hline Giardia lamblia cyst & $5(7.2)$ & $5(5.5)$ & $5(5.2)$ \\
\hline Ascaris lumbricoides & $17(24.6)$ & $23(23.1)$ & $23(23.7)$ \\
\hline Enterobius vermicularis & $4(5.8)$ & $5(5.5)$ & $5(5.2)$ \\
\hline Hymenolepis nana & $4(5.8)$ & $6(6.6)$ & $6(6.2)$ \\
\hline Hookworm spp. & $4(5.8)$ & $4(4.4)$ & $4(4.1)$ \\
\hline Schistosoma mansoni & $3(4.3)$ & $3(3.3)$ & $3(3.1)$ \\
\hline Strongyloides stecoralis & $12(17.4)$ & $15(15.4)$ & $15(15.5)$ \\
\hline Trichuris trichiura & $5(7.2)$ & $6(6.6)$ & $6(6.2)$ \\
\hline Taenia spp. & $5(7.2)$ & $12(13.2)$ & $12(12.4)$ \\
\hline A. lumbricoides and $H$. nana & 0 & $3(3.3)$ & $3(3.1)$ \\
\hline A. lumbricoides and Taenia spp. & 0 & $2(2.2)$ & $2(2.1)$ \\
\hline E. vermicularis and Taenia spp. & 0 & $\mathrm{I}(\mathrm{I} . \mathrm{I})$ & $\mathrm{I}(\mathrm{I} .0)$ \\
\hline T. trichiura and Taenia spp. & 0 & $\mathrm{I}(\mathrm{I} . \mathrm{I})$ & I (I.0) \\
\hline A. lumbricoides and $E$. histolytica & 0 & I (I.I) & I (I.0) \\
\hline Total & $69(18.0)$ & 91 (23.8) & $97(25.3)$ \\
\hline
\end{tabular}

Table 3 Prevalence of Intestinal Parasites Among HIV-Infected Individuals in Relation to Their CD4 ${ }^{+}$Count Attending ART Clinic at Debretabor General Hospital, Northern Ethiopia

\begin{tabular}{|c|c|c|c|c|}
\hline & \multicolumn{3}{|l|}{$\mathrm{CD4}^{+}$Category } & \multirow[t]{2}{*}{ P-Value } \\
\hline & $<200$ Cells $/ \mathrm{mm}^{3}, \mathrm{n}(\%)$ & 200-500 Cells/mm $3 \mathrm{~m}^{3}, \mathrm{n}(\%)$ & $>500$ Cells $/ \mathrm{mm}^{3}, \mathrm{n}(\%)$ & \\
\hline Giardia lamblia & $4(50)$ & I (12.5) & $3(37.5)$ & 0.201 \\
\hline Entamoeba histolytica & $7(100)$ & 0 & 0 & $0.035^{*}$ \\
\hline Ascaris lumbricoides & II (47.8) & $2(8.7)$ & $10(43.5)$ & 0.497 \\
\hline Enterobius vermicularis & $2(40)$ & 0 & $3(60)$ & 0.631 \\
\hline Hymenolepis nana & $2(33.3)$ & I (I6.7) & $3(50)$ & 0.521 \\
\hline Hook worm spp. & $2(50)$ & 0 & $2(50)$ & 0.784 \\
\hline Schistosoma mansoni & I (33.3) & 0 & $2(66.7)$ & 0.308 \\
\hline Strongyloides stecoralis & $6(40)$ & I (6.7) & $8(53.3)$ & 0.087 \\
\hline Trichuris trichiura & $2(33.3)$ & $2(33.3)$ & $2(33.3)$ & 0.161 \\
\hline Taenia spp. & $2(16.7)$ & $2(16.7)$ & $8(66.6)$ & 0.090 \\
\hline A. lumbricoides and $H$. nana & $2(66.6)$ & I (33.4) & 0 & 0.310 \\
\hline A. lumbricoides and Taenia spp. & I (50) & 0 & $\mathrm{I}(50)$ & 0.402 \\
\hline E. vermicularisand Taenia spp. & $I(100)$ & 0 & 0 & 0.140 \\
\hline T. trichiura and Taenia spp. & 0 & $I(100)$ & 0 & 0.212 \\
\hline A. lumbricoides and $E$. histolytica & $I(100)$ & 0 & 0 & 0.180 \\
\hline
\end{tabular}

Note: $* P<0.05$.

Africa. ${ }^{16}$ Intestinal parasitic infections are among the leading causes of morbidity and mortality in people living with HIV. The overall prevalence of intestinal parasites among patients in this study was found to be $25.3 \%$, which is comparable with reports from Axum, Ethiopia (26.4\%), ${ }^{17}$
Gondar, Ethiopia (24.3\%), ${ }^{18}$ Mozambique (26.5\%), ${ }^{19}$ and Brazil (24\%). ${ }^{20}$ This was higher than findings reported from the Kombolcha, Dessie, Gondar, and Kobo regions of Ethiopia and the Benin and Makurdi regions of Nigeria $(13.9 \%, \quad 17.6 \%, \quad 20 \%, \quad 16 \%, \quad 18 \%$, and $20.9 \%$, 
Table 4 Factors Associated with Intestinal Parasites Among HIVIAIDS Patients Attending ART Clinic at Debretabor General Hospital $(n=383)$ from December 2018 to March 2019

\begin{tabular}{|c|c|c|c|c|c|c|}
\hline \multirow[t]{2}{*}{ Category } & \multicolumn{2}{|c|}{ Intestinal parasitosis } & \multirow[t]{2}{*}{ COR $(95 \% \mathrm{Cl})$} & \multirow[t]{2}{*}{$P$-value } & \multirow[t]{2}{*}{ AOR $(95 \% \mathrm{Cl})$} & \multirow[t]{2}{*}{$P$-value } \\
\hline & Positive, N (\%) & Negative, $\mathbf{N}$ (\%) & & & & \\
\hline \multicolumn{7}{|l|}{ Age group } \\
\hline $18-35$ & $55(28.2)$ & | 40 (7I.8) & I.067 (0.520, 2.19I) & 0.859 & NA & \\
\hline $36-53$ & $29(20.1)$ & 115 (79.9) & $1.66(0.774,3.574)$ & 0.293 & NA & \\
\hline $54-65$ & $13(29.5)$ & 31 (70.5) & I & & & \\
\hline \multicolumn{7}{|l|}{ Sex } \\
\hline Male & $46(29.3)$ & III (70.7) & $1.271(0.799,2.023)$ & 0.212 & $1.025(.558,1.882)$ & 0.937 \\
\hline Female & $51(22.6)$ & $175(77.4)$ & I & & I & \\
\hline \multicolumn{7}{|c|}{ Level of education } \\
\hline Illiterate & $28(31.8)$ & $60(68.2)$ & $4.853(1.748,13.470)$ & $0.002 *$ & $4.165(1.394,12.450)$ & $0.011 *$ \\
\hline Read \& write & $16(4 I)$ & $23(59)$ & $7.235(2.366,22.120)$ & $0.001 *$ & $9.329(2.626,33.14)$ & $0.001 *$ \\
\hline Primary & $31(28.2)$ & $79(71.8)$ & $4.081(1.490,11.170)$ & $0.006^{*}$ & $3.515(1.192,10.36)$ & 0.063 \\
\hline Secondary & $17(19.1)$ & $72(81.1)$ & $2.456(0.850,7.080)$ & 0.096 & I.822 (0.592, 5.608) & 0.296 \\
\hline College \& above & $5(8.8)$ & $52(91.2)$ & I & & 1 & \\
\hline \multicolumn{7}{|l|}{ Water source } \\
\hline Tape water & $93(25)$ & $279(75)$ & 1 & & & \\
\hline Well water & $4(36.4)$ & $7(63.6)$ & $1.714(0.490,5.988)$ & 0.398 & NA & \\
\hline \multicolumn{7}{|c|}{ Presence of latrine } \\
\hline Yes & $85(24)$ & $269(76)$ & I & & 1 & \\
\hline No & $12(4 \mid .4)$ & $17(58.6)$ & $2.234(1.206,4.846)$ & 0.043 & $2.595(1.003,6.712)$ & $0.049 *$ \\
\hline \multicolumn{7}{|l|}{ Animal contact } \\
\hline Yes & $8(30.8)$ & $18(69.2)$ & $1.33(0.560,3.184)$ & 0.510 & NA & \\
\hline No & $89(24.9)$ & $268(75.1)$ & I & & & \\
\hline \multicolumn{7}{|c|}{ WHO clinical stage } \\
\hline I /II & $87(24.8)$ & $264(75.2)$ & 1 & & & \\
\hline $\mathrm{III} / \mathrm{IV}$ & $10(31.3)$ & $22(68.7)$ & I.379 $(0.629,3.020)$ & 0.422 & NA & \\
\hline \multicolumn{7}{|l|}{$\mathrm{CD4}^{+}$cells $/ \mathrm{mm}^{3}$} \\
\hline$<200$ & $44(57.1)$ & $33(42.9)$ & $3.42(1.929,6.094)$ & 0.000 & $3.359(1.793,6.293)$ & $0.000 *$ \\
\hline $200-500$ & II (7.I) & 145 (92.9) & $0.195(0.090,0.396)$ & 0.002 & $0.168(0.079,0.354)$ & 0.072 \\
\hline$>500$ & $42(28)$ & $108(72)$ & I & & 1 & \\
\hline
\end{tabular}

Note: * Statistically significant at $P<0.05$.

Abbreviations: $\mathrm{AOR}=$ adjusted odds ratio; $\mathrm{CD} 4^{+}=$cluster of differentiation; $\mathrm{COR}=$ crude odds ratio; $\mathrm{I}=$ reference group; $95 \% \mathrm{Cl}=95 \%$ confidence interval; $\mathrm{WHO}=$ world health organization; $\mathrm{NA}=$ not applicable.

respectively), ${ }^{5,12,21-24}$ though lower than reports from Cameroon $(57.48 \%),{ }^{25}$ Kenya $(50.9 \%),{ }^{26}$ and Burkina Faso $(73.3 \%)^{27}$ and studies conducted in different parts of Ethiopia, ie, Jimma $(44.8 \%)^{3}$ Jimma University Specialized Hospital (45.0\%), ${ }^{28}$ Hawassa $(47.8 \%),{ }^{7}$ and Shahura $(56.9 \%) .{ }^{9}$ This variation could be due to differences in sociodemographic characteristics, sample size, and time period. Additionally, implementation of relevant health-intervention programs and improvement in healthservice coverage with the active involvement of healthextension workers in some places might have contributed.

Despite not being statistically significant, the majority of intestinal parasites were detected among those aged 1835 years, the most productive and reproductive group in 
society, in line with a report from Gondar. ${ }^{22}$ Possible reasons might be frequent contact among one another, overcrowding in classrooms, poor personal hygiene, and habits of sharing materials that facilitate the spread of the parasites.The most predominant parasite was A. lumbricoides $(23.8 \%)$. This is in line with findings from studies in Jimma, ${ }^{29}$ Cameroon, ${ }^{25}$ and southeast Nigeria. ${ }^{30}$ In contrast to our finding, E. histolytica was the predominant parasite detected in ART clinics of a Kombolcha health center, ${ }^{21}$ northwestern Ethiopia, ${ }^{9}$ Gondar, ${ }^{22}$ Axum, ${ }^{17}$ and Kenya. ${ }^{26}$ Ubiquitous distribution, higher durability of eggs in diversified external environmental settings, the laying of many eggs, and poor socioeconomic status may contribute to an increased distribution of $A$. lumbricoides in the study area.

Among patients infected with intestinal parasites, about $41.4 \%$ did not have a toilet at home. Our study further revealed that not having a toilet at home was significantly associated with occurrence of intestinal parasitic infection, in line with a similar study from Gondar (AOR 5.21, 95\% CI $1.82-16.03){ }^{22}$ This is mainly due to the fact that absence of a toilet results in open-field defecation nearby homes, which leads easily to fecal-oral transmission of intestinal parasites. Similarly, this study also revealed that the prevalence of intestinal parasitic infections is significantly affected by level of education among HIV/AIDS patients. Illiterate patients had the highest prevalence of parasitic infection, in agreement with a study conducted in Nigeria. ${ }^{4}$ Moreover, significantly higher prevalence of intestinal parasites was found among patients with $\mathrm{CD} 4^{+}$ count $<200$ cells $/ \mathrm{mm}^{3}(P<0.0001)$, which is in agreement with reports from Gondar, $^{22}$ Nigeria, $^{31}$ and Mozambique. ${ }^{19}$ Therefore, reduction in $\mathrm{CD}^{+}$count to $<200$ cells $/ \mathrm{mm}^{3}$ in HIV patients increases the likelihood of acquiring opportunistic intestinal parasitic infections This is mainly because reduction in $\mathrm{CD}^{+}$cells due to HIV infection results in diminished cellular immunity, which is the major host-defense mechanism against intestinal parasitic infection.Despite not being statistically significant, increased rates of intestinal parasitic infections were detected among HIV patients categorized under WHO clinical stage I or II. This finding is in contrast to study reports from western Ethiopia, ${ }^{32}$ southern Ethiopia, ${ }^{33}$ and northeastern Ethiopia, ${ }^{12}$ which reported significantly higher proportions of intestinal parasitic infections from HIV patients categorized under WHO clinical stage III.

\section{Limitations}

Species-specific techniques, such as modified ZiehlNeelsen staining, Kato-Katz, Bearman's, and water-ether sedimentation for Microsporidia and intestinal Coccidia, were not done, due to lack of resources in the researchlaboratory setup. As such, the burden of intestinal parasites in this study might have been underestimated.

\section{Conclusion}

In this study, there was a moderately higher overall prevalence of intestinal parasites among HIV/AIDS patients, in contrast with other similar studies in the country. The distribution of intestinal parasites in the study area is greatly affected by illiteracy, lower immuno status $\left(\mathrm{CD}^{+}\right.$ T-cell count $<200$ cells $/ \mathrm{mm}^{3}$ ), and absence of a home toilet. Therefore, HIV/AIDS patients with low $\mathrm{CD}^{+}$ counts should be diagnosed consistently for intestinal parasites, and routine stool examination and awareness creation should be advocated to be included as an essential component of the ART-monitoring strategy for improved patient care. Moreover, large-scale longitudinal studies assessing all associated risk factors and continuous surveillance should be conducted to halt the spread of intestinal parasites among HIV patients.

\section{Abbreviations}

AOR, adjusted OR; ART, Anti-Retroviral Therapy; cd4, cluster of differentiation; COR, crude OR; FACS, fluorescence-activated cell sorting; WHO, World Health Organization.

\section{Acknowledgment}

The authors would like to acknowledge Debretabor Hospital ART clinic staff members and data collectors. Moreover, we acknowledge the study participants for their willingness and cooperation at the time of data collection.

\section{Author Contributions}

All authors made substantial contributions to conception and design, acquisition of data, or analysis and interpretation of data, took part in drafting the article or revising it critically for important intellectual content, agreed on the journal to which the article would be submitted, gave final approval to the version to be published, and agree to be accountable for all aspects of the work. 


\section{Funding}

No external funds were obtained, only institutional support from Debretabor University and Debretabor General Hospital.

\section{Disclosure}

The authors report no conflicts of interest in this work.

\section{References}

1. UNAID. UNAIDS Report on the Global AIDS Epidemic. Geneva: Switzerland: UNAID; 2019.

2. Teklemariam Z, Abate D, Mitiku H, Dessie Y. Prevalence of intestinal parasitic infection among HIV positive persons who are naive and on antiretroviral treatment in Hiwot Fana Specialized University Hospital, Eastern Ethiopia. ISRN AIDS. 2013;2013:1-6. doi:10.1155/ 2013/324329

3. Awol M, Gebre-Selassie S, Kassa T, Kibru G. Prevalence of intestinal parasites in HIV infected adult patients in south western Ethiopia. Ethiop. J. Health Dev. 2003;17(1):71-78.

4. Akinbo FO, Okaka CE, Omoregie R. Prevalence of intestinal parasitic infections among HIV patients in Benin City, Nigeria. Libyan $J$ Med. 2010;5:5506. doi:10.3402/ljm.v5i0.5506

5. Udeh EO, Obiezue RN, Ikele CB, Okoye IC, Otuu CA. Gastrointestinal parasitic infections and immunological status of HIV/AIDS coinfected individuals in Nigeria. Ann Glob Health. 2019;85(1):1-7.

6. Laksemi DA, Suwanti LT, Mufasirin M, Suastika K, Sudarmaja M. Opportunistic parasitic infections in patients with human immunodeficiency virus/acquired immunodeficiency syndrome: a review. Vet World. 2020;13(4):716-725. doi:10.14202/vetworld.2020.716-725

7. Fekadu S, Taye K, Teshome W, Asnake S. Prevalence of parasitic infections in HIV-positive patients in southern Ethiopia: a crosssectional study. J Infect Dev Ctries. 2013;7(11):868-872. doi: $10.3855 /$ jidc. 2906

8. Kiros H, Nibret E, Munshea A, Kerisew B, Adal M. Prevalence of intestinal protozoan infections among individuals living with HIV/ AIDS at Felegehiwot Referral Hospital, Bahir Dar, Ethiopia. Int $J$ Infect Dis. 2015;35:80-86.

9. Tigabu A, Taye S, Aynalem M, Adane K. Prevalence and associated factors of intestinal parasitic infections among patients attending Shahura Health Center, Northwest Ethiopia. BMC Res Notes. 2019;12(333):1-8. doi:10.1186/s13104-019-4377-y

10. Ngui R, Ishak S, Chuen CS, Mahmud R, Lim YA. Prevalence and risk factors of intestinal parasitism in rural and remote West Malaysia. PLoS Negl Trop Dis. 2011;5(3):e974. doi:10.1371/journal.pntd.0000974

11. Torgerson PR, Devleesschauwer B, Praet N, et al. World health organization estimates of the global and regional disease burden of 11 foodborne parasitic diseases: a data synthesis. PLoS Med. 2015;12 (12):e1001920. doi:10.1371/journal.pmed.1001920

12. Missaye A, Dagnew M, Alemu A. Prevalence of intestinal parasites and associated risk factors among HIV/AIDS patients with pre-ART and on-ART attending Dessie Hospital ART Clinic, Northeast Ethiopia. AIDS Res Ther. 2013;10(7):1-9. doi:10.1186/1742-640510-7

13. Alemu F. Prevalence of intestinal parasites and other parasites among HIV/AIDS patients with on-ART attending Dilla Referral Hospital, Ethiopia. J AIDS Clin Res. 2014;5(9):1-5. doi:10.4172/21556113.1000345

14. Cheesbrough M. District Laboratory Practice in Tropical Countries: 2nd Edition, Part 1. Cambridge: Cambridge University Press;; 2006.

15. BD Biosciences. BD FACS Count System Users Guide for Use with CD4/CD3 Reagent Kit; 2005 .
16. Ayesha BM, Kharsany AB, Karim QA, Infection HIV. And AIDS in Sub-Saharan Africa: current Status, Challenges and Opportunities. Open AIDS J. 2016;10:34-48. doi:10.2174/1874613601610010 034

17. Gebrewahid T, Gebrekirstos G, Teweldemedhin M, Gebreyesus H, Awala A, Tadla K. Intestinal parasitosis in relation to CD4 count and anemia among ART initiated patients in St. Mary Aksum general hospital, Tigray, Ethiopia. BMC Inf Dis. 2019;19:350.

18. Telele NF, Damte DG, Selassie S. Intestinal parasitic infections among HIV seropositives and seronegatives adult patients presented with diarrhea in Gondar, North west Ethiopia. Revi Ant Infec Dis. 2010;3:7-8.

19. Cerveja BZ, Tucuzo RM, Madureira AC, et al. Prevalence of intestinal parasites among HIV Infected and HIV Uninfected Patients Treated at the $1^{\circ}$ De Maio Health Centre in Maputo, Mozambique. EC Microbial. 2017;9(6):231-240.

20. Rodrigues Bachur TP, Vale JM, Branco Coelho IC, Sales Queiroz TRB, Souza Chaves C. Enteric parasitic infections in HIV/AIDS patients before and after the highly active antiretroviral therapy in Brazil. Braz J Infect Dis. 2008;12(2):115-122.

21. Gebretsadik D. Haileslasie H and Feleke DG. Intestinal parasitosis among HIV/AIDS patients who are on anti-retroviral therapy in Kombolcha, North Central, Ethiopia: a cross-sectional study. BMC Res Notes. 2018;11:613. doi:10.1186/s13104-018-37 26-6

22. Gebrecherkos T, Kebede H, Gelagay AA. Intestinal parasites among HIV/AIDS patients attending University of Gondar Hospital, northwest Ethiopia. Ethiop J Health Dev. 2019;33(2):64-72.

23. Bugssa G, Dimtsu G, Tarekegn H, Kassaw M, Tafete A. The prevalence of intestinal parasites in HIV positive and HIV negative individuals in Kobo Health Center, Northeastern Ethiopia: comparative cross sectional. Br Biomed Bull. 2014;2(3):56 $9-576$.

24. Akinbo FO, Okaka CE, Omoregie R. Prevalence of intestinal parasites in relation to CD4 counts and anaemia among HIV-infected patients in Benin City, Edo State, Nigeria. Tanzan J Health Res. 2011;13(1):8-13. doi:10.4314/thrb.v13i1.62986

25. Vouking MZ, Enoka P, Tamo CV, Tadenfok CN. Prevalence of intestinal parasites among HIV patients at the Yaoundé Central Hospital, Cameroon. Pan Afr Med J. 2014;18:136. doi:10.11604/ pamj.2014.18.136.3052

26. Kipyegen CK, Shivairo RS, Odhiambo RO. Prevalence of intestinal parasites among HIV patients in Baringo, Kenya. Pan Afr Med J. 2012;13(37):1-13.

27. Zida A, Yacouba A, Sawadogo MP, et al. Opportunistic and other intestinal parasites infections among HIV-positive patients in the era of combination antiretroviral therapy and preventive treatment in Ouagadougou, Burkina Faso. J HIV Clin Sci Res. 2017;4(1):0080014.

28. Kindie Y, Bekele S. Prevalence and risk factors for intestinal parasite infections in HIV/AIDS patients with anti-retroviral treatment in Southwest Ethiopia. J Trop Dis. 2016;4(3):1-4. doi:10.4172/2329891X.1000210

29. Zeynudin A, Hemalatha K, Kannan S. Prevalence of opportunistic intestinal parasitic infection among HIV infected patients who are taking antiretroviral treatment at Jimma Health Center, Jimma, Ethiopia. Eur Rev Med Pharmacol Sci. 2013;17:513-516.

30. Uju Marie-Esther D, Vincent E, Ilemobayo L, Akunnaya U. Intestinal parasitic infestations among people living with $\mathrm{HIV} /$ AIDS in Nsukka, Southeast Nigeria. Int J Curr Microbiol App Sci. 2013;2(11):539-550.

31. Akinbo FO, Anate PJ, Akinbo DB, et al. Risk factors of intestinal parasitic infections among human immunodeficiency virus-infected patients on highly active antiretroviral therapy. Port Harcourt Med J. 2017;11(1):15-20. doi:10.4103/phmj.phmj_5_17 
32. Dufera M, Petros B, Endeshaw T, Mohammed H, Kassu A Opportunistic intestinal protozoan parasites among HIV positive patients on antiretroviral therapy at Nekemte Hospital, west Ethiopia. Symposium on Sustainable Development: a great concern in Africa; 2010.
33. Abyu DM, Getahun EA, Malaju MT, Bizuayehu HM. Time to increase WHO clinical stage of people living with HIV in public health facilities of Arba Minch town, south Ethiopia. Clin Med Res. 2014;3(5):119-124. doi:10.11648/j.cmr.20140305.11

HIV/AIDS - Research and Palliative Care

\section{Publish your work in this journal}

HIV/AIDS - Research and Palliative Care is an international, peerreviewed open-access journal focusing on advances in research in HIV, its clinical progression and management options including antiviral treatment, palliative care and public healthcare policies to control viral spread. The manuscript management system is completely online and includes a very quick and fair peer-review system, which is all easy to use. Visit http://www.dovepress.com/testimonials.php to read real quotes from published authors. 